\title{
Mobile Phones in an Environment of Competing Survey Modes: Applying Metric for Evaluation of Costs and Errors
}

\author{
Vasja Vehovar ${ }^{1}$, Nejc Berzelak ${ }^{1}$, and Katja Lozar Manfreda ${ }^{1}$
}

This article was originally published in Social Science Computer Review 28(3): 303-318 by

Sage. The publisher's version of this article is available at:

https://journals.sagepub.com/doi/10.1177/0894439309353035.

Suggested citation: Vehovar, V., Berzelak, N., \& Lozar Manfreda, K. (2010). Mobile Phones in an Environment of Competing Survey Modes: Applying Metric for Evaluation of Costs and Errors. Social Science Computer Review, 28(3), 303-318. https://doi.org/10.1177/0894439309353035

\begin{abstract}
In recent years, mobile phones have become an increasingly important component in survey data collection. This holds true for self-administered questionnaires and particularly for interview sur-veys, where mobile phones enforce the combination with other survey modes. However, whether to include mobile phones in a particular survey design depends on complex cost-error relationships. To address this issue, the authors elaborate a metric-based on a product of costs and estimates of survey errors-that is then used for post survey comparison of design alternatives. The authors illustrate this approach with a simulation study using parameters from empirical research. The results show that such evaluation can potentially change the selection of the preferred design option compared to situations where only some of the components (e.g., response rate, nonresponse bias) are used for evaluation. More specifically, the decision about the inclusion of mobile phones predominantly depends on their bias-removing potential, while it is much less sensitive to changes in costs and other error parameters.
\end{abstract}

Keywords

survey errors, survey costs, bias, nonresponse, coverage, mobile phone survey

\section{Introduction}

Since the introduction of computers in the 1970s and through the emerging role of the Internet in the 1990s, information and communication technology (ICT) has been continuously transforming the process of survey data collection. New devices and communication protocols have enabled the development of numerous new survey options. Within this context, a mobile phone plays an important role because it is the most personal among all communication devices and it enables contact with almost the entire active population. In addition, it offers both self- and interviewer-administered surveys. In the future, we can expect eliminated, or at least minimized, current country-specific barriers (expensive per minute charges, complicated pricing models, legal

\footnotetext{
${ }^{1}$ University of Ljubljana, Faculty of Social Sciences, Slovenia

Corresponding Author:

Katja Lozar Manfreda, University of Ljubljana, Faculty of Social Sciences, Kardeljeva Ploscad 5, 1000

Ljubljana, Slovenia Email: katja.lozar@fdv.uni-lj.si
} 
restrictions, technological problems, lack of standardization, a complex relationship between mobile and fixed telephone coverage rates), which today bring considerable complexity for the full implementation of mobile phones into the survey data collection process. Despite that, computer-assisted telephone interviewing using mobile phones (i.e., mobile CATI) is becoming an increasingly frequent option replacing face-to-face and fixed telephone interviews (Gallup Europe, 2009). Similarly, computerized self-administered questionnaires on the mobile phone (i.e., mobile CSAQ) are becoming a serious alternative to PC-based Web surveys. In addition, mobile phone surveys can be a component in various types of mixed-mode settings (de Leeuw, 2005). For example, respondents can be offered different mode alternatives, one of them being calling a toll-free mobile tele-phone number in addition to a Web survey. Similarly, a call to a mobile phone can be used on nonrespondents of the previous wave where a less intrusive mode (e.g., Web or mail survey) was used, or different modes can be used to separate target segments (e.g., mobile phones in one segment/country and fixed telephones in another). Mobile phones can also be used in subsequent waves of the survey panels (after the first contact was done in person), as well as in specific data collection sessions, for example, first a personal interview over a mobile phone is performed, then a few sensitive items are answered using SMS or WAP.

Finding an optimal mixture of the survey modes is a very complex task because of countless alter-natives for which data quality and corresponding costs need to be considered. However, compared to extreme practical importance of this issue in survey practice, the literature dealing simultaneously with data quality and survey costs is surprisingly rare. For example, in a review of empirical studies comparing different survey formats, Dolnicar, Laesser, \& Matus (2009) found that numerous criteria had been used in comparisons (response rate, speed, item omission, sample representativity) with only $30 \%$ of the studies also investigating the costs. Similarly, studies comparing mobile phone surveys with other modes usually have focused merely on response rates or on differences in responses (e.g., Brick, Edwards, \& Sunghee, 2007; Callegaro et al., 2007; Vehovar, Belak, Batagelj, \& Cikić, 2004). We can find only anecdotal evidence about higher survey costs in mobile phone interview surveys (e.g., Kuusela, Callegaro, \& Vehovar, 2007; Pew Research Center, 2008). One of the rare published studies that directly compared the survey costs of a mobile phone versus fixed telephone survey was conducted by Link, Battaglia, Frankel, Osborn, \& Mokdad (2007).

In contrast to the above studies, we apply here an integrative and very general approach for comparing cost and errors of alternative survey designs. The metric for comparison is based on the concept of the mean squared error (MSE) - as a common measure for survey errors (Hansen, Hurwitz, \& Madow, 1953) - and its relation to survey costs. We have been inspired by optimization approaches where comparisons of costs and MSE were mentioned (Lyberg, Japec, \& Biemer, 1998) or fully elaborated (Deming, 1953; Kish, 1965; Groves, 1989). However, in classical sampling theory, all cost-error components were first explicitly modeled and then optimized analytically, whereas here we only apply the metric of standardized calculations for costs and errors to past surveys. The product of costs and the estimate for survey errors (i.e., MSE) are used here as a basis for ranking of different design alternatives. Our approach can be thus applied only for the comparison of already implemented or simulated survey design alternatives using existing data about costs and errors. Results of such comparison can be then used to make informed decisions about the 
most cost-effective survey design. Expansion to a priori optimization-as in classical sampling literature - is not within the scope of this article but is briefly discussed.

The proposed approach is very general and can be conceptually applied to any survey design, including those that consider mobile phones. There exists in fact a very strong quest in survey practice (e.g., Gallup Europe, 2009) for quantitative support to elaborate criteria related to the inclusion of mobile phones into survey projects, either in unimode or in mixed-mode surveys. Particularly, the use of mobile CATI - with its complicated and expensive practical implementation on one side, but also with powerful bias-removing characteristics on the other-is becoming one of the essential dilemmas in contemporary surveys of the general population. We believe that the approach outlined in this article can contribute to the quantification of the elements that are essential for the decision about including mobile phones into a survey design.

In the following sections, we first (Mobile Phones in Survey Data Collection) overview the role of mobile phones in contemporary survey industry. Next (Cost-Error Comparison: A Theoretical Approach), we present a theoretical approach for evaluating survey errors and costs, which is then applied in a comparison of alternative survey designs, including ones with the mobile phone survey option (Simulation Study). In the discussion, we summarize the results and outline future research.

\section{Mobile Phones in Survey Data Collection}

In the past decade, mobile phones have become an integral part of everyday life (Goggin, 2006). Lately, their usage has also entered into the survey industry by offering a rich array of new possibilities for survey data collection. Text messages on mobile phones can be used for recruiting, inviting, and otherwise contacting respondents (Bosnjak, Neubarth, Couper, Bandilla, \& Kaczmirek, 2008; Steeh, Buskirk, \& Callegaro, 2007), for follow-up contacts (Virtanen, Sirkia“, \& Jokiranta, 2007), as well as for a tool for quality control (Kuusela et al., 2007). Short message service (SMS), wireless application protocol (WAP), and mobile Internet options allow collection of survey responses by the means of computerized self-administered questionnaires (i.e., mobile CSAQ; Fuchs, 2007). In particular, mobile phones can be used in interviewer-administered computer-assisted telephone surveys (i.e., mobile CATI). In this article, we predominantly focus on mobile CATI, which seems to be gaining momentum (Brick \& Tucker, 2007; Callegaro et al., 2007; Kauffman \& Techatassanasoontorn, 2005; Kuusela et al., 2007). However, while in the future mobile CSAQ might replace current Web surveys, at the moment it still has only a negligible share in the overall volume of the survey data collection (Macer, 2009).

One of the key problems of contemporary interviewer-administered surveys over the fixed tele-phone lays in a growing number of "mobile-only" households, which are often different from the rest of the population (Blumberg, Luke, \& Cynamon, 2006; Kuusela et al., 2007). In some countries, such as Finland, Lithuania, Latvia, Czech Republic, this share already exceeds $50 \%$ of the households (Gallup Europe, 2009). This creates a potential for serious noncoverage bias in fixed telephone surveys, which in practice has been shown to range from being ignorable or only moderate (Blumberg et al., 2006; Keeter, 2006; Keeter, Kennedy, Clark, Tompson, \& Mokrzycki, 2007) up to very substantial (Blumberg et al., 2006; Link et al., 2007; Vehovar et al., 2004), depending on the survey topic and country specifics. As a consequence, the survey industry is forced to increase the combination of the modes and devices. For example, the Flash Eurobarometer survey (Gallup Europe, 2009) is now forced to replace standard fixed telephone surveys with mixed-mode ones, 
either as a combination of fixed and mobile phone surveys (Spain, Italy, Portugal, Austria, Finland) or as a combination of fixed telephone and face-to-face interviews (Poland, Czech Republic, Estonia, Latvia, Lithuania, Hungary, Slovakia, Romania, Bulgaria).

In addition to the above-described coverage problem, there exists a whole array of other methodological problems related to mobile phone surveys: absence of sampling frames, unlisted numbers, prepaid mobile phones, the specifics related to personal nature of mobile phone devices, the inability to separate mobile phone numbers from fixed ones, the prefixes that are not necessarily indicative of geographic location, double coverage in dual frame designs, weighting procedures, mode effects, measurement errors, and problems with response rates (Callegaro et al., 2007; Kuusela et al., 2007; Lavrakas, Shuttles, Steeh, \& Fienberg, 2007). The studies comparing response rates of mobile and fixed CATI have often given contradicting results, from lower rates in mobile CATI (Link et al., 2007; Vehovar et al., 2004), through comparable results (Pew Research Center, 2008) to higher rates in mobile CATI (Gallup Europe, 2009). This holds similarly for the length of the interview, which is reported to be longer on mobile CATI by some studies (Brick et al., 2007) and also shorter by others (Fuchs, 2006). We must be specifically aware of potential mode effects related to the interview over the mobile phone, which are however very difficult to isolate and detect.

Despite all methodological challenges, survey practitioners believe that mobile phone surveys can be a reliable data collection option, if a proper methodological approach is undertaken. As a consequence, we can observe a rapid increase in their usage. However, their most inconvenient characteristic is related to the costs, which have been found uniformly higher in comparison to fixed telephone surveys (Kuusela et al., 2007; Link et al., 2007; Pew Research Center, 2008).

With some simplifications, we can say that the inclusion of the mobile CATI into the contemporary telephone surveys (mostly within a mixed-mode setting) may remove the noncoverage bias and it may increase response rates, while it definitely increases the costs. The quantification of all these aspects and their integration to support decisions about including this mode into a particular survey project are thus becoming an increasingly important methodological issue, highly relevant for survey practice.

\section{Cost-Error Comparison: A Theoretical Approach}

In every survey, we optimize different aspects of data quality - such as survey errors, accuracy, relevance, timeliness and punctuality of results, accessibility and clarity of information, comparability, coherence, completeness, etc. (Biemer \& Lyberg, 2003)within given budgetary constraints. On one hand, the whole survey data collection process can be regarded as a business process and as such nested in a broader context of business optimization, where standard quality concepts can be applied (such as cost-benefit analysis, Total Quality Management, Six Sigma, etc.). On the other hand, in survey practice, smaller components of the survey data process are also optimized, such as the workload of interviewers, the number of solicitation waves, response rates, calling strategy, and so on. In this article, we limit ourselves to the optimization of the survey design (which can be a combination of different modes and types of data collection) by minimizing total survey error as the most elaborated (Groves, 1989) and essential - although not exhaustivecomponent of data quality. Within this context, we first discuss survey errors and survey costs. Next, we elaborate criteria for their simultaneous evaluation. 


\section{Survey Errors}

In the literature, we can find certain diversity in considerations of survey errors (Biemer \& Lyberg, 2003; Groves, 1989, 2005; Groves et al., 2004; Lessler \& Kalsbeek, 1992; Weisberg, 2005). The classification may start with separation of errors of observation from nonobservation, with random errors from biases, or with sampling from nonsampling errors (and further decomposing the latter into those related to specification, frame, nonresponse, measurement, and processing). Here, we limit the discussion to the total survey error that is also viewed as the accuracy of a survey estimate, expressing an expected magnitude of a difference between an estimate and its true population value (Groves, 1989). These differences may have systematic sources (ones that produce consistent effects over replications of a particular survey design) and are referred to as biases or random sources and are referred to as variance (Groves et al., 2004) or random errors. We will express the total survey error for a particular survey item with a standard approach of a MSE (Deming, 1950; Hansen et al., 1953; Kish, 1965) summing up the variance and the bias component:

$$
\operatorname{MSE}(\bar{y})=\operatorname{Var}(\bar{y})+\operatorname{Bias}^{2}(\bar{y})
$$

where the bias part is defined as:

$$
\operatorname{Bias}(\bar{y})=E(\bar{y})-\bar{Y}
$$

that is, the difference between expected mean of our estimator and the true mean of our variable in the population.

The above equations present the calculation of the MSE only for the estimate of mean, that is, average value, as the most widely used estimated parameter in the survey research literature. Of course, it is also possible to discuss the MSE for the estimates of other parameters, such as correlations or regression coefficients.

When calculating and estimating the MSE with the above equations, we may face various practical problems. First, the MSE can be calculated for one survey item at a time, and it may behave differently for different items. Second, obtaining a true population value is one of the most prominent issues when estimating the bias. This unknown value can be only known on the basis of some auxiliary data, such as population registers, or estimated with some other more reliable surveys (e.g., face-to-face survey is sometimes declared as the "gold standard"' to which other modes are com-pared). In addition, when comparing MSEs from different survey design alternatives (as in our case), it is very difficult to separate random errors from biases and it is also very complicated to separate components of the bias (or random errors) among themselves. Namely, the MSE is usually a combined result of sampling error, noncoverage, nonresponse, misspecification, measurement, and pro-cessing error (Groves, 1989). Particularly in mixed-mode surveys, it is difficult to isolate the mode effect bias and also the corresponding mode effect random error.

The total survey error (expressed with the MSE) is, of course, only one specific measure of the survey data quality. Its key benefit is that it takes into account various error sources, although in practice it is sometimes difficult to measure and separate between them. As mentioned, it also excludes various other data quality components. Nevertheless, comparing the MSE among alternative survey designs is superior to approaches that focus 
on one or few error sources only (such as comparing only sampling errors, response rates, or biases).

\section{Survey Costs}

Although the formalization of survey errors is relatively well elaborated in the literature, this is not the case with survey costs. Groves (2006) relates this problem to the gaps in the understanding of the production process, the cost data, and the organizational culture. It is also difficult to establish a universal cost model that would apply to a variety of survey situations and environments. For complex cost models, difficulties of providing adequate data input become a major obstacle. In addition, such models usually bring little added value compared to simple ones (Karr \& Last, 2006; Kish, 1965). Nevertheless, in this subsection, we will still conceptualize a very general cost model, which is, how-ever, still a linear one.

To estimate costs of different survey designs, it is first necessary to separate survey solicitation activities from data collection ones (Vehovar \& Lozar Manfreda, 2008). Solicitation (i.e., invitation to a survey) as a separated activity can be performed together and with the same mode as the corresponding data collection (e.g., as in fixed telephone or face-to-face surveys) or, increasingly often, with a different communication mode. This conceptual separation is especially important in complex mixed-mode survey systems with numerous combinations possible. For example, an initial contact (first wave) can be a mail invitation to complete either a Web or a paper questionnaire (two modes offered simultaneously); in a second wave nonrespondents from the first wave can be contacted (e.g., with up to five calls) and interviewed through the telephone (either fixed or mobile), while in the third wave the remaining nonrespondents are paid a personal visit (e.g., up to three visits).

The following equation takes into account the separate structure of solicitation and data collection costs for different options of the modes within each wave:

$$
C=c_{0}+\sum_{k=1}^{K} \sum_{m=1}^{M}\left(c_{0_{k, m}}+c_{k, m} \cdot n_{k, m}\right)+\sum_{k=1}^{K} \sum_{m=1}^{M}\left(a_{0_{k, m}}+a_{k, m} \cdot r_{k, m}\right) \text {, }
$$

Solicitation

Data collection

where $n_{k, m}$ and $r_{k, m}$ denote number of units in certain wave $(k)$ and mode $(m)$.

We have up to $\mathrm{K}$ solicitation and data collection waves, and within each of them there are $\mathrm{M}$ possible modes. There exist some general fixed costs $\left(\mathrm{c}_{0}\right)$. In addition, each wave (solicitation and data collection) and each mode within this wave may have its own additional fixed costs $\left(\mathrm{c}_{0 \mathrm{k}, \mathrm{m}}, \mathrm{a}_{0 \mathrm{k}, \mathrm{m}}\right)$, independent of the number of units assigned at that level. Here, we keep the fixed costs constant within a specific design, what is a realistic assumption for moderate changes in sample size. Of course, if the sample size in a certain component radically increases, for example, by factor 10, some of the corresponding fixed costs parameters may change. We then treat such a design as a different one, with new fixed costs parameters, so that the above equation still works.

For each mode $\mathrm{m}$ within a certain wave $\mathrm{k}$, there are also specific variable costs attached to each unit in the process, that is $\left(c_{k, m}, a_{k, m}\right)$, for solicitation and data collection correspondingly.

Sometimes, a practical estimation of survey costs using the structure above needs certain arbitrary estimates. For example, clear separation between solicitation and data collection costs does not always exist in interviewer-administered survey modes (e.g., telephone surveys), so the first minute of the conversation can be arbitrarily allocated to the 
solicitation stage. Nevertheless, despite the apparent complexity, our experience shows that in practice the calculation and desegregation of the costs according to the above equation is a workable task.

\section{Cost-Error Optimization}

We combine here costs and errors by calculating the product of their estimates. The minimization of this product is a standard approach in classical sampling literature, particularly for stratification and cluster sampling (e.g., Cochran, 1978; Hansen et al., 1953; Kish, 1965), although limited there only to the product of the costs and sampling variance (and not the MSE). More recently, the com-bination of MSE and costs was also exposed by Lynn and Elliot (2000) and particularly by Lyberg et al. (1998), who say that "using MSE as a guide, we can begin to address the cost-error trade-offs" (p. 23). Empirical applications of this approach are rare (Vehovar \& Lozar Manfreda, 1998; Vehovar, Lozar Manfreda, \& Batagelj, 2001). Most explicitly, however, we encounter such an approach in nonresponse optimization double sampling (Deming, 1953; Elliott, Little, \& Lewitzky, 2000; Harter, Mach, Wolken, \& Chapline, 2007). In part, specific alternative survey designs were also evaluated with a similar concept by Linacre \& Trewin (1993) and Westling (2008). However, none of these examples discussed the comparison of more general mixed-mode design.

There are three options when establishing a relationship between costs and errors (i.e., MSE) of alternative survey designs. We can look for

1. a design providing a required fixed MSE of a target survey variable and having the lowest costs. This may be used when having very clear requirements regarding the accuracy of survey estimates (e.g., unemployment rate in Labor Force Surveys);

2. a design with the lowest MSE of a target survey variable for a given fixed budget. This is, in fact, the usual approach where data quality follows and adapts to the available budget;

3. the smallest product of costs and MSE for a target survey variable in each competing survey design option. This is the most flexible approach when we perform comparisons among different design solutions at various initial sample sizes.

In the empirical example further on, we use the third approach that provides the most illustrative insight into the performance of different survey design alternatives. In addition, it enables comparisons based on a fixed final sample size of alternative designs, which is a very common request from clients.

\section{Limitations and Further Development}

The presented approach provides proper cost-error calculations for a set of past- and predefined survey designs that were already implemented or simulated. In this case, we dispose with all needed data on costs and errors to calculate products of MSE costs. This enables us to rank alternative survey designs and identify the one with the lowest product value. As mentioned in the introduction, we do not address here the problem of optimization algorithms, which would find a new optimal structure and combination of the modes for a specific survey. This would be a very complex task. Only in cases of simple cost-error models with one mode, one wave of solicitation and with sampling variance as the only MSE component, we could derive the optimal sample design structure analytically 
with a straight-forward elaboration of the Schwartz inequality as in Kish (1965). How-ever, for more complex models, the analytical solution is almost impossible. Even the maximization of the response rate - which is one specific subcomponent of the total survey error-would lead to a simplex-type of the problem and complex linear programming due to a recursion process (Vehovar, Kveder, \& Perman, 2000). However, it is true that for each and every survey project, there exists a real person (i.e., researcher, manager, client) who actually does perform these calculations, including the consideration of all costs, implicit bias modeling (i.e., relation between response rate and bias) for all variables within each mode, and also the optimization itself. Of course, this person usually considers only rough estimates of the key cost-error parameters, together with a lot of implicit assumptions. Similarly, he or she performs only a very approximate optimization. It is therefore reasonable to assume that a specific computer algorithm would perform much better in processing and optimizing these large and complex data. This might be an area of further development of our approach into which, however, we do not enter here.

\section{Simulation Study}

We illustrate our approach with a simulation of the survey design alternatives using parameters from empirical research. More specifically, examples presented below provide quantitative evaluations that can help in a decision related to the inclusion of the designs that involve the mobile CATI.

\section{Competing Survey Design Alternatives}

Parameters used in simulations were obtained from a survey on ICT usage among households in Slovenia, a survey coordinated by Eurostat (2008). The Statistical Office of the Republic of Slovenia (SORS) fielded this survey in April-May 2008, using the Central Population Register (CPR) as a sampling frame and a split sample design with face-to-face and fixed telephone mode (designs 4 and 5 in Table 1). At the same time, the Faculty of Social Sciences (FSS), University of Ljubljana, per-formed experiments based on the same questionnaire (Berzelak, Vehovar, \& Lozar Manfreda, 2008). We include here three of those experimental design cells (designs 1-3 in Table 1). Additional designs including mobile CATI were simulated using continuous FSS experience with these surveys 
Table 1. Basic Characteristics of Compared Survey Design Alternatives

\begin{tabular}{|c|c|c|c|}
\hline Survey Design & Organization & $\begin{array}{l}\text { Sampling } \\
\text { Frame }\end{array}$ & Procedure \\
\hline (1) Web/mail & FSS & CPR & $\begin{array}{l}\text { 1st wave: mail invitation to complete a Web questionnaire } \\
\text { 2nd wave: mail follow-up for nonrespondents with repeated } \\
\text { invitation to the Web and include a paper questionnaire } \\
\text { 3rd wave: mail reminder for nonrespondents to complete the } \\
\text { paper or the Web questionnaire }\end{array}$ \\
\hline $\begin{array}{l}\text { (2) Web/mail with } 5 € \\
\text { incentive }\end{array}$ & FSS & CPR & $\begin{array}{l}\text { Same as above, with an incentive of } 5 € \text { in cash provided in the } \\
1 \text { st wave to all sample units }\end{array}$ \\
\hline (3) Mail & FSS & CPR & $\begin{array}{l}\text { 1st wave: a mail prenotification (without a questionnaire) } \\
\text { 2nd wave: a paper questionnaire by mail } \\
\text { 3rd wave: a reminder for nonrespondents to complete the } \\
\text { paper questionnaire }\end{array}$ \\
\hline (4) Fixed CATI & SORS & CPR & $\begin{array}{l}\text { 1st wave: a mail prenotification (without a questionnaire) } \\
\text { 2nd wave: a CATI survey (up to five follow-ups) }\end{array}$ \\
\hline (5) Face-to-face & SORS & CPR & $\begin{array}{l}\text { 1st wave: a mail prenotification (without a questionnaire) } \\
\text { 2nd wave: face-to-face interviewing }\end{array}$ \\
\hline $\begin{array}{l}\text { (6) Mobile CATI } \\
\text { (simulated) }\end{array}$ & FSS & RDD & Mobile phone survey with up to 5 follow-up calls \\
\hline $\begin{array}{l}\text { (7) Mobile CATI with } \\
5 € \text { incentive } \\
\text { (simulated) }\end{array}$ & FSS & RDD & $\begin{array}{l}\text { Mobile phone survey with up to five follow-up calls, plus } 5 € \\
\text { incentive for respondents }\end{array}$ \\
\hline $\begin{array}{l}\text { (8) Fixed and mobile } \\
\text { CATI (simulated) }\end{array}$ & FSS & $\begin{array}{l}\text { CPR } \\
\text { RDD }\end{array}$ & Combination of (4) and (6) in proportion 2:1 \\
\hline
\end{tabular}

CATI $1 / 4$ computer-assisted telephone interviewing; CPR $1 / 4$ Central Population Register; FSS $1 / 4$ Faculty of Social Sciences;

RDD $1 / 4$ Random Digit Dialing; SORS $1 / 4$ Statistical Office of the Republic of Slovenia.

a Sample units (selected from CPR) were assigned a fixed telephone number obtained from the telephone directory. If the fixed number was not found, a mobile telephone number was looked for in the telephone directory. If none of them was found, the unit was omitted from surveying. At the end, the share of mobile phone interviews among all units was so small (4\%) that we regard this design as fixed telephone mode.

since 2003 (Vehovar et al., 2004): a stand-alone Random Digit Dialing (RDD) mobile CATI (6); a stand-alone RDD mobile CATI with an incentive of $5 €$ transferred to the accounts of respondents

(7); and a dual frame design with fixed CATI and RDD mobile CATI (8). For each of these mobile CATI options, we additionally varied response rates and biases.

Because of budget restrictions, only individuals aged 18-50 years were included into the FSS experiments and also into all calculations below.

In Slovenia, the mobile phone coverage rate is $90 \%$ (Zdešar \& Zupan, 2008), similar to other European Union (EU) countries. Despite that, the survey industry in Slovenia in general has not been including the mobile phones into surveys of the general population, predominantly because of high costs but also because fixed telephones still provide $70 \%$ household coverage, while the mobile-only segment is only around $15 \%$. Nevertheless, the unfavorable trends are increasingly pressing the industry to consider and test this option. The approach outlined below may help in making a more informed decision on this dilemma. 


\section{Estimation of Costs and Errors}

We used a detailed cost breakdown structure-following the equation from the Survey Costs - to calculate corresponding cost parameters from empirical data. Some country specifics include: less expensive low-tax student (interviewer) work, inexpensive fixed and mobile telephone calls with mobile per minute charges three times higher than fixed ones, short travel distances for face-to-face interviewers (due to the smallness of the country), and relatively high printing and posting costs. These all reduce the costs of the intervieweradministered surveys compared with the mail option.

Regarding survey errors, we limit here on bias (due to nonresponse, noncoverage, mode effect, etc.) and on sampling error. We omitted other random error components of the MSE (e.g., inter-viewer variance, random measurement error, random processing error; Biemer \& Lyberg, 2003), because

1. we share a common practice of the vast majority of past research (e.g., Groves, 1989; Hansen et al., 1953; Kish, 1965; Lavrakas et al., 2007; etc.), which predominantly focuses on sampling error as the only random component in MSE;

2. we focus here on general principles of how to simultaneously discuss costs and errors, so additional components of random errors can be added according to the specifics of a certain survey;

3. this simplification enables us to keep our approach sufficiently general, but at the same time also feasible for empirical calculations.

For the purposes of the illustration, we selected here a variable "age of respondents," because we dispose with its value (from the CPR). In addition, age is highly correlated with various target variables on ICT usage and also with the selected survey designs (e.g., age is usually overestimated in fixed CATI and underestimated in mobile CATI or Web-related modes), what gives additional interest to this example.

Within this context and for simplicity of the demonstration, we do not separate the bias subcomponents (i.e., noncoverage, nonresponse, mode effect bias), although this could be of course further elaborated. In addition, it could be reasonable to assume in our example that the mode-effect bias is negligible, because of the factual nature of the variable " age." In general, of course, certain mode effect may exist when comparing personal and telephone interviews (de Leeuw \& van der Zouwen, 1988; Tucker \& Lepkowski, 1991), telephone and Web (Fricker, Galesic, Tourangeau, \& Ting, 2005), or mail and Web surveys (Carini, Hayek, Kuh, Kennedy, \& Ouimet, 2003; Huang, 2006). Most often, however, such a bias arises with attitudinal variables, particularly with those having a social desirability component.

We may also add that in our example we assume having no noncoverage in mail and face-to-face designs (sampling from high quality CPR), while in telephone surveys we already mentioned that we have a $30 \%$ noncoverage for fixed CATI and a $10 \%$ for the mobile one. Of course, nonresponse exists in all design alternatives in our examples, and the corresponding nonresponse bias generally dominates in the MSE.

The results are presented in Table 2. Due to various reasons, the surveys were implemented with different initial sample sizes; however, for the sake of costs comparison, the sample sizes were rescaled to 1,000 responding units for all designs. This might additionally mix and confound the estimates of the bias with those of the sampling error, because we did not adjust the estimates of the biases for the changes in sampling error when 
rescaling (with smaller sample sizes the estimates of the bias are inevitably larger). However, as this rescaling was moderate and due to demonstrational purposes, we still preferred such a solution. All other parameters (i.e., response rates, response values, cost components) were taken from actual empirical surveys.

\section{Results}

The results in Table 2 confirm findings from various meta-analytical studies (e.g., Gallup Europe, 2009; Groves \& Peytcheva, 2008) that higher response rates do not necessarily correlate with lower

Table 2. MSE and Costs Across Survey Designs for Fixed Final Sample Size of 1,000 U for the Variable Age

\begin{tabular}{|c|c|c|c|c|c|c|c|}
\hline Survey Design & Initial $\mathrm{n}$ (Eligible) & $\begin{array}{l}\text { Response } \\
\text { Rate (\%) }\end{array}$ & $\begin{array}{l}\text { Mean } \\
\text { Age (y) }\end{array}$ & Bias $^{a}$ & MSE & Costs $(€)$ & MSE $\times$ Costs \\
\hline 1. Web/mail & $3,215(3,215)$ & 31 & 32.7 & 2.16 & 4.75 & 7,200 & 34,205 \\
\hline 2. Web/mail with $5 €$ incentive & $1,410(1,410)$ & 71 & 32.0 & 2.81 & 7.99 & 10,758 & 85,956 \\
\hline 3. Mail & $3,425(3,425)$ & 30 & 33.4 & 1.39 & 92.05 & 8,726 & 17,845 \\
\hline 4. Fixed CATI & $2,451(2,441)$ & 41 & 35.5 & 0.68 & 30.56 & 9,011 & 5,044 \\
\hline 5. Face-to-face & $1,616(1,592)$ & 63 & 35.5 & $0.6 s$ & 0.57 & 28,911 & 16,418 \\
\hline
\end{tabular}

CATI $1 / 4$ computer-assisted telephone interviewing; MSE $1 / 4$ mean squared error.

a The true value from the Central Population Register (CPR) is 34.8 years.

biases. Especially illustrative is the case of the Web/mail survey with incentives (Design 2) having the highest bias despite the highest response rate (71\%). High costs of this design combined with a high bias make it actually the worst among all options if we observe the product of the MSE and costs. In contrast, the face-to-face survey (Design 5) with a response rate of $63 \%$ provided a much better estimate and is the second best design, regardless of by far the highest costs. The face-to-face option is outperformed by the significantly cheaper fixed CATI (Design 4) with very low response rate (only 41\%) but with a small bias. We can thus summarize that a higher response rate - which is often the parameter to optimize in survey practice-dramatically failed in predicting the optimal design. Similarly, it is true also if we observe only the bias or only the MSE, ignoring the costs.

In the above comparison, the only variability we have within a certain survey design is the increasing efforts to lower nonresponse rate (and hopefully also bias). Of course, lower nonresponse can also be obtained with alternative designs (e.g., varying the combination of survey modes). In any case, the important question here concerns the relation between the nonresponse rate and the non-response bias. This relation is usually unknown; however, conceptually we may think of the three most frequent options illustrated in Figure 1.

A. The nonresponse bias decreases with the increasing response rate, which is the usual (implicit) assumption when pursuing high response rates.

B. The nonresponse remains unchanged regardless of the higher response rates until nearly all units have responded; here, the efforts for increased response rate would be worthless. This is perhaps the prevailing assumption in opinion and marketing research.

C. In the first stages of the survey process, the nonresponse bias may even increase with the increasing response rates, which is the case with the Design 2 in the Table 2. This 
is an example where incentives and subsequent follow-ups contribute to a high response rate but are disproportionately more effective for specific segments that results in a larger nonresponse bias.

Based on the possible relationships in Figure 1, we simulated six scenarios involving the mobile CATI, which are then compared to the fixed CATI (Design 4 in Table 2), the optimal design in the empirical study (now listed first and shaded in Table 3):

- Scenario 1 (based on the assumption A): The response rate in the RDD mobile CATI is lower and correspondingly the bias is higher than in the fixed CATI. This is the most typical assumption about the behavior of the nonresponse bias.

- Scenario 2 (based on the assumption B): The response rate in the RDD mobile CATI is lower than in the fixed CATI, while the bias is similar (although in the opposite direction, assuming that the fixed CATI overrepresents older while the mobile CATI overrepresents younger per-sons). This scenario corresponds to the real situation in Slovenia, so it is shaded lightly.

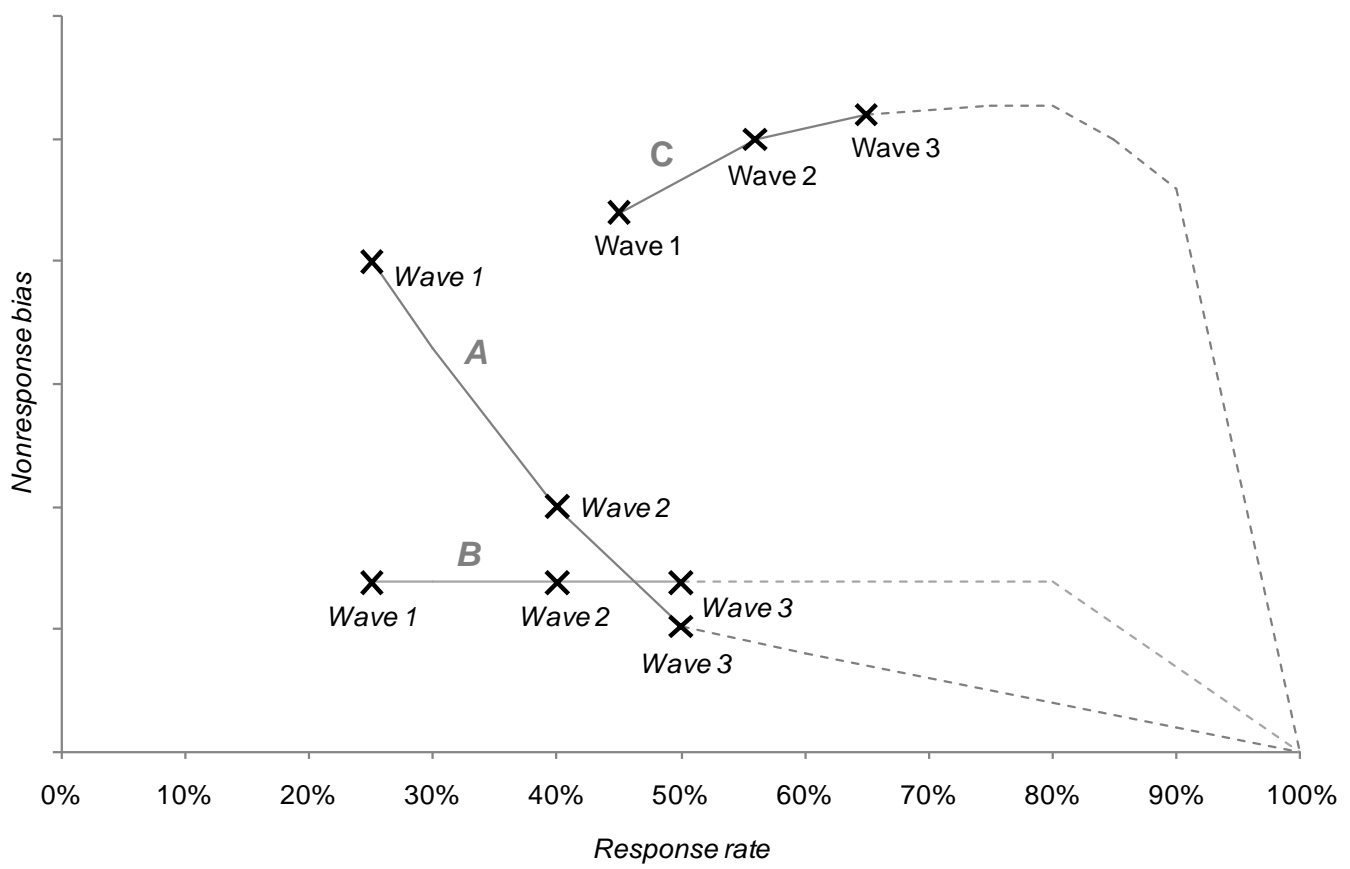

Figure 1. Illustration of possible relations between response rate and nonresponse bias: $(A)$ bias decreases with higher response rate; (B) bias remains unchanged until very high response rate; (C) bias temporarily increases with higher response rate. The relation are illustrated for a design with three waves of data collection. 
Table 3. Comparison of MSE and Costs: Fixed CATI (Conventional Telephone Survey) and Different Scenarios of the RDD Mobile CATI at the Fixed Final Sample Size of 1,000 U

\begin{tabular}{|c|c|c|c|c|c|c|c|}
\hline Design/Scenario & $\begin{array}{l}\text { Initial }^{\mathrm{a}} \\
\text { (Eligible) }\end{array}$ & $\begin{array}{l}\text { Response } \\
\text { Rate (\%) }\end{array}$ & Estimate & Bias $^{b}$ & MSE & Costs $(€)$ & MSE $\times$ Costs \\
\hline$\overline{\text { Fixed CATI }}$ & $2,451(2,441)$ & 41 & 35.5 & 0.68 & $\overline{0.56}$ & $\overline{9,011}$ & $\overline{5,044}$ \\
\hline RDD mobile CATI (Scenario 1) & $8,000(4,000)$ & 25 & 31.0 & 3.81 & 14.6 & 13,546 & 197,771 \\
\hline RDD mobile CATI (Scenario 2) & $8,000(4,000)$ & 25 & 34.1 & 0.69 & 0.57 & 13,546 & 7,721 \\
\hline RDD mobile CATI (Scenario 3) & $4,000(2,000)$ & 50 & 34.1 & 0.69 & 0.57 & 9,086 & 5,211 \\
\hline RDD mobile CATI (Scenario 4) & $4,000(2,000)$ & 50 & 34.3 & 0.51 & 0.34 & 9,086 & 3,089 \\
\hline $\begin{array}{l}\text { RDD mobile CATI with } 5 € \\
\text { incentive (Scenario } 5 \text { ) }\end{array}$ & $3,076(1,538)$ & 65 & 31.2 & 3.61 & 13.13 & 13,355 & 175,351 \\
\hline $\begin{array}{l}\text { 1/3 RDD CATI p 2/3 fixed } \\
\text { CATI (Scenario 6) }\end{array}$ & $4,290(2,955)$ & 34 & 35.0 & 0.20 & 0.14 & 10,743 & 1,504 \\
\hline
\end{tabular}

CATI $1 / 4$ computer-assisted telephone interviewing.

${ }^{a}$ Number of randomly generated mobile phone numbers needed for the RDD mobile CATI scenarios.

$\mathrm{b}$ True value from the Central Population Register (CPR) is 34.8 years.

${ }^{c}$ Values obtained from the empirical study.

${ }^{d}$ Regarded as the most realistic scenario for mobile CATI in Slovenia.

- Scenario 3 (based on the assumption B): The response rate in the mobile CATI is higher than in the fixed CATI, while the bias is similar but in the opposite direction, which is similar to Scenario 2. Scenario 4 (based on the assumption A): The response rate in the mobile CATI is higher and the bias is lower than in the fixed CATI (opposite direction compared to Scenario 1), what was reported for some countries (Gallup Europe, 2009).

- Scenario 5 (based on the assumption C): The response rate in RDD mobile CATI with incentive is higher, but the bias is also higher than in the fixed CATI. This would occur if incentives additionally attracted younger respondents to the mobile CATI, resulting in a higher response rate, but also in a higher bias, similar to the Design 2 from the Table 2.

- Scenario 6 (based on the assumption B): The dual frame design combines fixed CATI with RDD mobile CATI from the Scenario 2 in proportion $2: 1$. As a consequence, the response rate is in between, while the bias is smaller, as the two biases offset each other.

In the Scenario 1, the RDD mobile CATI design is more expensive, with lower response rate and higher bias than the fixed CATI, what is all reflected in the high product of the MSE and costs. The high costs can primarily be attributed to the low response rate, which imposes a larger initial sample. However, if the bias of the RDD mobile CATI equaled the fixed CATI-despite a lower response (the assumption B about nonresponse rate-bias behavior) - this would be (Scenario 2) the second best solution in comparison to the actual five designs from Table 2. Of course, if the response rate in the RDD mobile CATI significantly exceeded the response rate in the fixed CATI (Scenario 3), this would then fully compare with the fixed CATI design. Scenario 4 assumes even better conditions for the RDD mobile CATI, with higher response rate and lower bias. Doubling the response rate to $50 \%$ and lowering the bias would make the RDD mobile CATI very cost-effective. With incentives (Scenario 5), the response rate is assumed to move to $65 \%$ (from $25 \%$ ). The estimate for this difference (40\%) arises from the empirical data (Design 2 in Table 2) 
in Slovenia. Similar to Design 2 from Table 2, we assume that the incentive would disproportionately attract younger segments, resulting in additional bias, so the cost-error ratio is very unfavorable. The last Scenario 6 presents the dual frame situation, combining response rates and biases from the fixed CATI and the RDD mobile CATI from the most realistic Scenario 2. As the biases from both components offset each other, this lowers the combined bias. Despite slightly higher costs than in the fixed CATI, this is found to be the best among all designs in our simulations. This design is, roughly speaking, perhaps also the most likely direction for the future of telephone surveys in Slovenia, where a further increase is expected in the fixed telephone noncoverage, as well as in the share of "mobileonly' households.

By summarizing the interpretations of the above scenarios, we could say that only significant gains in the bias can make the inclusion of mobile phones into the survey data collection reasonable. The variations in other components (e.g., costs) have much lesser effect.

Of course, many other combinations and scenarios may be considered. However, in the above illustrations, we selected both the typical and the extreme cases to demonstrate that a decision about optimal design combination should be subject to quantification and simultaneous consideration of errors and costs.

\section{Discussion}

In this article, we studied an approach to compare costs and errors of competing survey designs. This is becoming an increasingly critical problem as the progressive need for combining survey modes urges researchers to establish procedures to evaluate the design alternatives. The mobile phones play a particularly important role here, because they provide almost complete coverage of the general population and can thus replace fixed telephone surveys, which suffer from an increasing noncover-age problem. On the other side, the mobile alternative brings higher costs, complex administration, and various unresolved methodological issues.

In the proposed approach, we used the MSE as a measure of the data quality, while for costs we elaborated a general cost function, where we (a) separated the solicitation and data collection components and (b) included the option for combining modes within each wave of solicitation or data collection. For the comparison, we used the product of the costs and the MSE, an approach used already in classical sampling literature, although in other contexts. Such a product expressed the cost-error relationship, which can be alternatively interpreted also, as the costs per unit of accuracy, the latter being measured as an inverse of the MSE.

We illustrated this approach with empirical data and with simulation designs addressing a very practical question related to whether (and under what circumstances) to include mobile CATI as an alternative for surveys of general population. We found that the simultaneous integration of the costs and errors radically changed ranking of the preferred design alternatives when compared to usual criteria based only on coverage rates, nonresponse rates, lowest biases, costs, and so on. The most sensitive parameter in this cost-error model was the bias, which dominated the MSE even in our situation of relatively 
small sample sizes. This implies that the assumptions about the behavior of the bias are the most crucial for the selection of the design that involves mobile phones.

We performed simulations with a very specific variable ("age of respondents") that had several advantages, as justified in the Estimation of Costs and Errors. Of course, factual variables, such as age, are usually much less robust to nonresponse and noncoverage problems than attitudinal ones. As a consequence, our choice may exaggerate the sensitivity to cost and error parameters, particularly to the assumptions about the bias-response behavior. Apart from this, the bias in sociodemographic variables can be removed through some weighting adjustments.

We should mention that outside this article we actually did perform the analysis also for various other variables, that is, for the share of the Internet users and for the share of singleperson house-holds (Berzelak et al., 2008). We also studied averaged biases across all variables in weighted data sets (Lozar Manfreda, Berzelak, \& Vehovar, 2009). Although these results differ somehow from the ones presented above (where only the "age" variable was used), they bring no added value to the illustration of our methodological approach, because they basically confirmed that (a) the integration of costs radically changed the ranking of the optimal designs compared to the partial criteria and that (b) the highest sensitivity of the results exists with respect to the assumptions about the behavior of the bias.

When applying this approach in practice, various obstacles may arise. We frequently do not know much about the nature and extent of the bias nor do we know much about its relation to the response rates. This urges researchers to put more efforts into the investigation and evaluation of the bias and its components (e.g., noncoverage, nonresponse, mode effect bias) for past surveys and also to elaborate more explicitly the assumptions about the rate-bias relationship.

In our experience, the estimation of costs was a relatively straight-forward process with very few obstacles, while there were more problems concerning the error part, particularly with respect to the above-mentioned assumptions about the relationship between the response rate and the nonresponse bias. There, we were forced to make our implicit assumptions fully explicit and include them in the simulation designs. Of course, better and more justified assumptions lead to better results.

The work outlined in this article presents an initial step toward more elaborated approaches to support the decisions related to the selection of an optimal survey design. Our approach may be further expanded to include analytical solutions to parts of this problem or may lead to some computer-automated procedures for the comparison of competing survey designs. This may be further extended to unit level algorithms where, within a given cost model, within a given sampling error estimation model, and particularly within a given (assumption) model for the rate-bias relationship, some automated procedure would evaluate a large number of alternatives and propose the optimal decision (i.e., the selection of the most appropriate solicitation and data collection mode) for each unit at each wave of the survey. Such procedures may even be performed in real time, where a priori knowledge (e.g., data from the sampling frame, cost parameters, response rate, and response bias assumptions) can be combined with posterior information from the previous waves of the same sur-vey (e.g., certain sociodemographics, type of refusal, contact information). 


\section{Declaration of Conflicting Interests}

The authors declare that there is no conflict of interest.

\section{Funding}

This work was supported by the Slovenian Research Agency, project identifier J7-0004.

\section{References}

Berzelak, N., Vehovar, V., \& Lozar Manfreda, K. (2008, August). Nonresponse in web surveys within the con-text of survey errors and survey costs. Paper presented at the 2nd MESS Workshop, Zeist, The Netherlands.

Biemer, P. P., \& Lyberg, L. E. (2003). Introduction to survey quality. Hoboken, NJ:

Wiley.

Blumberg, S. J., Luke, J. V., \& Cynamon, M. L. (2006). Telephone coverage and health survey estimates: Evaluating the need for concern about wireless substitution. American Journal of Public Health, 96, 926-931.

Bosnjak, M., Neubarth, W., Couper, M. P., Bandilla, W., \& Kaczmirek, L. (2008). Prenotification in web-based access panel surveys: The influence of mobile text messaging versus e-mail on response rates and sample composition. Social Science Computer Review, 26, 213-223.

Brick, J. M., Edwards, W. S., \& Sunghee, L. (2007). Sampling telephone numbers and adults, interview length, and weighting in the California health interview survey cell phone pilot study. Public Opinion Quarterly, 71, 793-813.

Brick, J. M., \& Tucker, C. (2007). Mitofsky-Waksberg: Learning from the past. Public Opinion Quarterly, 71, 703-716.

Callegaro, M., Steeh, C., Buskirk, T. D., Vehovar, V., Kuusela, V., \& Piekarski, L. (2007). Fitting disposition codes to mobile phone surveys: experiences from studies in Finland, Slovenia and the USA. Journal of the Royal Statistical Society: Series A (Statistics in Society), 170, 647-670.

Carini, R. M., Hayek, J. C., Kuh, G. D., Kennedy, J. M., \& Ouimet, J. A. (2003). College student responses to Web and paper surveys: Does mode matter? Research in Higher Education, 44, 1-19.

Cochran, W. G. (1978). Sampling techniques (3rd ed.). New York: John Wiley.

de Leeuw, E. D. (2005). To mix or not to mix data collection modes in surveys. Journal of Official Statistics, 21, 233-255.

de Leeuw, E. D., \& van der Zouwen, J. (1988). Data quality in telephone and face to face surveys: A compara-tive meta-analysis. In R. M. Groves, P. P. Biemer, L. E. Lyberg, J. T. Massey, W. L. Nicholls II \& J. Waksberg (Eds.), Telephone survey methodology (pp. 283-299). New York: John Wiley.

Deming, W. E. (1950). Some theory of sampling. New York: John Wiley. 
Deming, W. E. (1953). On a probability mechanism to attain an economic balance between the resultant error of response and the bias of nonresponse. Journal of the American Statistical Association, 48, 743-772.

Dolnicar, S., Laesser, C., \& Matus, K. (2009). Online versus paper: Format effects in tourism surveys. Journal of Travel Research, 47, 295-316.

Elliott, M., Little, R. J. A., \& Lewitzky, S. (2000). Subsampling callbacks to improve survey efficiency. Journal of the American Statistical Association, 95, 730-738.

Eurostat. (2008). Community survey on ICT usage in households and by individuals2008. Luxembourg: Author.

Fricker, S., Galesic, M., Tourangeau, R., \& Ting, Y. (2005). An experimental comparison of Web and telephone surveys. Public Opinion Quarterly, 69, 370-392.

Fuchs, M. (2006, January). Nonresponse and measurement error in mobile phone surveys. Paper presented at the 2nd International Conference on Telephone Survey Methodology, Miami, FL.

Fuchs, M. (2007). Mobile web surveys: A preliminary discussion of methodological implications. In F. G. Conrad M. F. Schober (Eds.), Envisioning the Survey Interview of the Future (pp. 77-94).

Hoboken, NJ: Wiley. Gallup Europe. (2009, February). Presentation Technical workshop. Paper presented at the Eurobarometer Technical Workshop, Budapest, Hungary.

Goggin, G. (2006). Cell phone culture: Mobile technology in everyday life. London, UK: Routledge.

Groves, R. M. (1989). Survey errors and survey costs. Hoboken, NJ: Wiley.

Groves, R. M. (2005, March). Total survey error: Past, present, and future. Paper presented at the Total Survey Error Workshop, Washington, DC.

Groves, R. M. (2006, April). Survey budgets, cost models, and responsive survey designs. Paper presented at the Survey Cost Workshop, Washington, DC.

Groves, R. M., Fowler, F. J., Couper, M. P., Lepkowski, J. M., Singer, E., \& Tourangeau, R. (2004). Survey methodology. Hoboken, NJ: Wiley.

Groves, R. M., \& Peytcheva, E. (2008). The impact of nonresponse rates on nonresponse bias: A meta-analysis. Public Opinion Quarterly, 72, 167-189.

Hansen, M. H., Hurwitz, W. N., \& Madow, W. G. (1953). Sample survey methods and theory. New York: Wiley.

Harter, R., Mach, T., Wolken, J., \& Chapline, J. (2007, June). Determining subsampling rates for nonrespon-dents. Paper presented at the Third International Conference on Establishment Surveys, Montréal, Canada.

Huang, H. -M. (2006). Do print and Web surveys provide the same results? Computers in Human Behavior, 22, 334-350.

Karr, A. F., \& Last, M. (2006). Survey Costs: Workshop Report and White Paper. Workshop held in April 2006, Washington, DC.

Kauffman, R. J., \& Techatassanasoontorn, A. A. (2005). Is there a global digital divide for digital wireless phone technologies? Journal of the Association for Information Systems, 6, 338-381.

Keeter, S. (2006). The impact of cell phone noncoverage bias on polling in the 2004 presidential election. Public Opinion Quarterly, 70, 88-98. 
Keeter, S., Kennedy, C., Clark, A., Tompson, T., \& Mokrzycki, M. (2007). What's missing from national land-line RDD surveys? Public Opinion Quarterly, 71, 772-792.

Kish, L. (1965). Survey sampling. New York: Wiley.

Kuusela, V., Callegaro, M., \& Vehovar, V. (2007). The influence of mobile telephones on telephone surveys. In J. M. Lepkowski, C. Tucker, J. M. Brick, E. D. de Leeuw, L. Japec, P. J. Javrakas, et al. (Eds.), Advances in telephone survey methodology (pp. 87-112). Hoboken, NJ: Wiley.

Lavrakas, P. J., Shuttles, C. D., Steeh, C., \& Fienberg, H. (2007). The state of surveying cell phone numbers in the United States: 2007 and beyond. Public Opinion Quarterly, $71,840-854$.

Lessler, J. T., \& Kalsbeek, W. D. (1992). Nonsampling error in surveys. New York:

Wiley.

Linacre, S. J., \& Trewin, D. J. (1993). Total survey design-Application to a collection of the construction industry. Journal of Official Statistics, 9, 611-621.

Link, M. W., Battaglia, M. P., Frankel, M. R., Osborn, L., \& Mokdad, A. H. (2007). Reaching the U.S. cell phone generation: Comparison of cell phone survey results with an ongoing landline telephone survey. Public Opinion Quarterly, 71, 814-839.

Lozar Manfreda, K., Berzelak, N., \& Vehovar, V. (2009, August). Can Web be an alternative to expensive face-to-face/telephone surveys of the general population? Comparison of survey errors \& costs. Paper presented at the 3rd Workshop on Measurement and Experimentation with Internet Panels, Santpoort, the Netherlands.

Lyberg, L. E., Japec, L., \& Biemer, P. P. (1998). Quality improvement in surveys-A process perspective. Paper presented at the Survey Research Methods Section, American Statistical Association, US.

Lynn, P., \& Elliot, D. (2000). The British Crime Survey: A review of methodology. London, UK: National Centre for Social Research.

Macer, T. (2009, February). Mobile technology in research: Trends and perspectives. Paper presented at the Mobile Research Conference 2009, London, UK.

Pew Research Center. (2008, December 18). Calling cell phones in '08 pre-election polls. News Release. Retrieved February 20, 2009, from http://peoplepress.org/reports/pdf/cell-phone-commentary.pdf

Statistical Office of the Republic of Slovenia. (2008). Community survey on ICT usage in households and by individuals_-2008 [Survey data for Slovenia]. Ljubljana, Slovenia: Statistical Office of the Republic of Slovenia.

Steeh, C., Buskirk, T. D., \& Callegaro, M. (2007). Using text messages in U.S. mobile Tucker, C., \& Lepkowski, J. M. (1991). An evaluation of the 1988 current point-ofpurchase CATI feasibility test. Paper presented at the Survey Research Methods Section.

Vehovar, V., Belak, E., Batagelj, Z., \& Cikić, S. (2004). Mobile phone surveys: The Slovenian case study. Metodološki zvezki (Advances in Methodology and Statistics), 1, 1-19. 
Vehovar, V., Kveder, A., \& Perman, M. (2000, September). Calling Strategy as a Sequence of Linear Optimi-zation Problems. Paper presented at the 11th International Workshop on Household Survey Nonresponse, Budapest, Hungary.

Vehovar, V., \& Lozar Manfreda, K. (1998). How many mailings are enough? In A. Koch \& R. Porst (Eds.), Nonresponse in survey research (pp. 139-149). Mannheim: Zentrum für Umfragen, Methoden und Analysen.

Vehovar, V., \& Lozar Manfreda, K. (2008). Overview: Online surveys. In N. G. Fielding, R. M. Lee, \& G. Blank (Eds.), The handbook of online research methods (pp. 177194). Thousand Oaks, CA: Sage.

Vehovar, V., Lozar Manfreda, K., \& Batagelj, Z. (2001). Sensitivity of electronic commerce measurement to the survey instrument. International Journal of Electronic Commerce, 6, 31-52.

Virtanen, V., Sirkia“, T., \& Jokiranta, V. (2007). Reducing nonresponse by SMS reminders in mail surveys. Social Science Computer Review, 25, 384-395.

Weisberg, H. F. (2005). The total survey error approach: A guide to the new science of survey research. University of Chicago Press.

Westling, S. (2008). A simulation approach to evaluate the cost efficiency of nonresponse follow-ups. Working Paper series, Handelshögskolan vid Orebro universitet. Retrieved September 7, 2009, from http:// www.oru.se/oruupload/Institutioner/Ekonomi\%20statistik\%20och\%20informatik/Forskning/wp200811.pdf

Zdešar, P., \& Zupan, G. (2008, November 28). Internet usage in households, Slovenia, $1^{\text {st }}$ quarter 2008. E-Release. Retrieved March 3, 2008, from

http://www.stat.si/eng/novica_prikazi.aspx?id $1 / 42027$

\section{Bios}

Vasja Vehovar, PhD, is a professor of statistics at the Faculty of Social Sciences, University of Ljubljana. The main areas of his research interest include the problem of survey nonresponse, Web survey methodology, and social aspects of the Internet and other ICTs. He may be reached at vasja.vehovar@fdv.uni-lj.si.

Nejc Berzelak is a researcher at the Faculty of Social Sciences, University of Ljubljana. His research work is primarily focused on methodological issues of Web surveys and on utilization of other new technologies in social science data collection. He may be reached at nejc.berzelak@fdv.uni-lj.si.

Katja Lozar Manfreda, $\mathrm{PhD}$, is an assistant professor at the Faculty of Social Sciences, University of Ljubl-jana. Her research interests include survey methodology, new technologies in social science data collection, and Web survey methodology. She can be reached at katja.lozar@fdv.uni-lj.si. 